\title{
License for Professionalizing Education in Egypt as A Way for Professionalizing Teacher's Job
}

\author{
Prof/ Howida Mahmoud Eletrebi \\ ${ }^{1}$ Professor of education fundamentals, \\ Faculty of Education, \\ Tanta University \\ hwaida.elatrebi@edu.tanta.edu.eg
}

\begin{abstract}
The issue of preparing teachers has been a forcing concern for a lot of educators in Egypt especially at the age of rapid technological changes. So, certain rules should be issued to guarantee choosing the best teachers; the thing which cannot be achieved without professionalizing education by issuing licenses for working as teachers. The license of professionalizing the job of teachers is considered an acknowledgement of the teacher's ability to teach. In addition, this license encourages teachers to develop themselves and upgrade their imaginative thinking for a long time. There must be an official department to issue this licence according to regulations and criteria corresponding with the necessary regulations for doing the teaching effectively and efficiently.
\end{abstract}

Keywords: license - professionalizing education - Egypt - professionalizing teacher's job

\section{Introduction}

As being considered a primary source for producing knowledge and culture, universities compete hard to invest their resources and choosing the best alternatives and priorities to form a kind of scientific and intellectual thinking for humans. Also, universities are forced to make good use of these different resources by providing a number of activities and programs for teaching staff which is defined by vocational development.

It's clear that a lot of faculties of education in different countries suffer from problems of preparing teachers. (Taraman\& Adalor, 2016, 1603-1630) refers that teaching social studies in the USA and Turkey suffer from few practices and applications which must include all years of study not the last year only. However, USA amended that problem but turkey still suffers.

The study of ilgaz (2019, 204 -214) shows that faculties of education in Turkey try to help students only to memorise and repeat not to understand. Teachers of social studies stated that they would benefit greatly from training courses targeting teachers to be able to teach well.

Education at Egyptian universities suffers from numerous problems which put obstacles in the way of achieving desirable developmental role for many reasons: increasing the number of students, the low capacity of study system and concrete potentials which aren't able to absorb all these students.

In addition, the faculty of education lacks in objective criteria and basics which may attract students who face so many problems after graduation including the severe competition with Arab and foreign teachers, the low status of teachers and deficiencies of programs of preparing the teachers who are led to aside the job of a teacher especially males. In order to issue the licence of professionalising the job of a teacher, some questions must be answered:

1- What is the philosophical frame for the licence?

2- What are the universal experiences concerning issuing the teacher licence?

3- What are the suggested mechanisms for professionalising the job of teaching in Egypt? 
In order to know the circumstances of issuing licence for teacher's job and the final teaching's requirements and demands besides universal experiences and necessary mechanisms for that licence, the researcher depended on the critical analysis through the following axes:

First axis: Philosophical criterion for Licensing teacher's job:-

- After getting general secondary certificate, students join the faculty of education for four years. Once completing study there, students who succeed are awarded a bachelor of arts and education, which is called complementary system. On the other hand, graduates of faculty of arts and science can be enrolled in higher studies department in faculties of education to obtain bachelor of education, which is called consequential system.

- Since the success of educational system is dependent on existing of efficient teachers, the profession of teaching requires a sort of proficiency in the vocational preparation of teachers which aims at developing teachers' Thoughts and production especially during the age of challenges. Thus, teachers are morally responsible for engineering humans' minds during those challenges which affect society greatly and impose new roles on teachers who must be aware of the following:-

- *First: Concept of the licence of professionalising teaching:-

- The issue of professionalising teaching has played an important role in arising the need for a licence for teachers who must keep up with the new educational trends to be able to get that licence in the light of the age requirements. Licence for teachers mean a process by which a certain official department can grant authorization for Proficient and clever teachers to practise teaching regionally or internationally. That licence should be ruled by certain criteria through which a teacher can pass fixed courses and tests designed by accredited establishment to aside non efficient teacher from learners' way. That licence, also, is considered an official document which has a date of expiry. It shows desirable rules teachers should do according to vocational regulations.

Second: Goals of the licence for teachers:-

-Selecting the best cadres and teachers to prepare a strong generation of learners to face challenges of the age.

-emphasizing the importance of lifelong learning principle to help teachers get the licence of teaching to qualifying learners who are able to develop their knowledge.

--Making sure that those teachers are knowledgeable and vocationally distinguished to help evaluate them in the life long development.

- -Evaluating teachers from time to time to make them aware of innovations of the technological revolution; the thing which is considered a motivation for teachers to upgrade themselves by developing their skills and doing training courses.

- Helping teachers to reach the best performance and rules in the light of technology and information age besides encouraging those teachers to improve their profession.

- Helping teachers by introducing feedback to teachers in order to be vocationally graduated.

Third: The Need For Licencing The Job Of Teacher:

Teaching is considered one of the most supreme and important jobs in all societies. Thus, the licence of working as a teacher is the most important base for reforming education. There are many reasons for issuing that licence including:

1-It's a sort of adaptation to all changes resulting from technological resolutions specially globalisation, space exploration and using computers in everyday life.

2-Catching up with the latest advancement in the society to make students adaptable to their societies.

3 -Issuing the licence is necessary to put teachers in good position in society besides providing them with knowledge and proficiencies required in the field of teaching.

4-It's important to make teaching job respectable and appreciated by students and their parents.

5-It's necessary to protect learners from non-efficient teachers or non-qualified ones.

6-Catching up with the latest changes in the field of teaching which led to:

- Change From Stability To Flexibility.

- Change From Conservation To Innovation.

- Change From Temporary Learning To Lifelong One.

- Change From Consuming Knowledge To Producing It.

- Change From Intellectual Obsession To Intellectual Security.

- Change From Tyranny To Democracy.

\section{Fourth: criteria of the teacher licence:}

- Issuing teachers' licence is done according to fixed and objective criteria made by educational experts. Teachers are asked to pass tests relating to that licence which has an expiry date.

- In 1987, national board for professionalising teaching standards (NBPTS) started to issue certificates for expert teachers to authorize other teachers to practise that job. According to NBPTS, a teacher must have a bachelor degree, three years of experience and a valid teaching licence. As for teachers of general education, they have to obtain master degree and sufficient years of experience to be able to get NBC. In addition, applicants for a teacher's licence have to do six computers-based standard practises concerning the contents of the primary education, secondary one or the English language. To be added, after completing 
three years of practise programme, the licence becomes valid for ten years. The certificate of NBPTS tries to cover five suggestions:

1. Teachers' adhering to students' needs and how they are committed to encouraging students.

2. Competence in teaching different subjects to students.

3. Sticking to controlling students.

4. Ability of searching for the new educational methods to teach students.

5. A teacher should play a role in education communities (Bolson\& Housted, 2015, 1-21).

There are certain requirements to get that licence:

- A university certificate from a certified institution.

- Participating in training courses.

- Passing tests and competitions.

- Passing interviews.

- Completing higher studies.

- Getting the nationality of the country during working as a teacher there.

* Fifth: overview about the license of teachers:

- In the 1940s, the national Association of education has established a national committee in America to set effective rules based on standards to produce teachers who are able to teach well and pass standardized tests to get the teaching license.

- In the early 1980s, USA issued what is called alternative teaching license for university graduates who want to work as teachers without a need for the vocational preparation so that they can satisfy vacant jobs in math and science at schools (Flippo, 2002, p211). However, that try faced a lot of criticism because of the low standard of teachers ;the thing which led to applying a number of regulating procedures to make teaching stick to criteria and regulations by which it can be ruled.

- In the mid-1980, USA issued two important records: Holmes Association "tomorrow teachers" and Carnegie forum about economic learning "ready nation or $21^{\text {st }}$ century teachers". The former report recommended licensing a teacher's profession into three categories: professional teachers, Apprentice teachers and assistant teachers. The latter report recommended designing a national plan for issuing the teachers license.

- In 1987, NBPTS has been established in order to develop education levels and defining necessary skills teachers must have to obtain a teacher's license issued by each state.

- NBPTS puts some criteria to enable teachers to get vocational certificates. Experts try to develop and improve knowledge and skills of teachers besides providing them with computer -based tests. Certificates take five years to be issued (United States Department of education, 2018, p7).

\section{The second axis: the most famous global experiences in issuing teachers' licenses.}

\section{First: - USA experience:}

In the USA, every state is responsible for issuing licenses for teachers but these states differ in some practices as follows:

In North Carolina, education Council adapted the following policies:

1-It adopted the main principles and recommendations of the National Council for teaching criteria .

2-Giving licenses of teaching for teachers who got the certificate of NBPTS outside North Carolina •

3-Adopting the development of plans announced by the National Council of the State.

North Carolina has put five criteria for getting the teaching license: leadership, good environment for pupils, acknowledging curricula, making education available for all pupils and the training teachers on new practices (North Carolina Mentor program, 2010, 30 ) .

In New York, the license requires passing the following tests:

1) Passing (NYSTC) test for science and Arts to evaluate

teachers of Elementary and secondary stages .

2) Passing writing tests (AST-W).

3) Passing the national test NYSTCE) for teachers of music, art or special education. In order to obtain teachers' license, a number of tests affiliated by Minnesota board of teaching must be passed:

1) Certified exams in Reading, writing and math.

2) Certified exams in general educational knowledge.

3) Certified exams in the subject of the specialization.

4) A general exam for all the previous components.

In 2015, a law was issued to grant teachers' license for those who are from Minnesota (Hawkins, 2016) However, the process of issuing licenses in Minnesota is confusing and needs being reformed because authorizing licenses is divided between Minnesota board of teaching and department of teaching ;the thing which makes it difficult to control issuing licenses according to laws. Consequently, the legislative authority in Minnesota recommended unifying the process of issuing licenses to be under control of only governmental authorities (solvejg, 2016).

In Washington which hosts a great number of certified teachers from the National board of teaching, it is clearly noted that teachers affiliated by NPBTS certificate are 
more effective than their peers who haven't got that certificate yet especially teachers of math in Elementary schools (Cowana and Gold hob, 2016. 233 -258).

\section{Secondly: United Kingdom experience:}

In the United Kingdom, a teacher is required to get a qualified teacher status(QTS) and the general England council for teaching certificate of being a qualified teacher after completing the training and the preparation program for beginner teachers at an official educational Foundation(GTC, 2011).QTS provides a teacher with vocational properties which are necessary for any teacher, vocational knowledge and the skills besides the necessity of passing three basic tests in math, reading, writing and instructional technology (GTC, 2011).

A number of criteria have been put by the department of education for evaluating the teachers to get QTS:

1-Advanced expectation to excite students' motivation.

2-Reinforcing the positive development and instruction inputs.

3-Studying the contents of curricula.

4-Preparing for teaching well and in a defined way.

5- A Teacher has to get on with his students' abilities.

6-Fruitful benefit from feedback and evaluation.

7-Running the vocational behavior effectively to keep the learning environment safe.

Third: Japan experience.

After completing a study of the faculties of education in Japan the would-be teachers have to do a 30-hour program of vocational development besides passing the following:

1- Passing the written exams in the general and academic subjects.

2- Passing interviews.

3- Passing practical tests at the physical education and fine arts.

4- Passing tests in the Japanese language.

- Japan includes 47 estates with each one of them has an Education Council. Also, the minister of education is responsible for appointing the supervisors of education in every State in order to issue licenses for teachers at Elementary and secondary schools. The Education Council of every state is authorized to appoint teachers after checking exams' results especially of those who have the highest and the most suitable qualifications. Japan awards teachers a three-year temporary certificate by which a teacher cannot practice teaching except in his municipality (Akipa, 2013).
- By referring to the previous experiences, Egypt policy sticks to some important criteria:

1) Passing the academic and the general tests: linguistic communication, class management, time management and educational evaluation.

2) Getting high qualifications at least to get the license.

3) The license should have an expiry date.

4) Training before work for a period of time before getting the license.

*Third axis: suggested mechanisms for licensing teachers' job in Egypt. There are three mechanisms:

1- Before joining the faculty of education:

It is necessary for students to undergo an aptitude test before joining the faculty as some faculties do such as faculty of polytechnic, fine arts, physical education and the faculty of qualitative education. At the same time, it's important for students to choose the suitable department corresponding with their abilities.

2-The role of education faculty in upgrading educators' performance by the following procedures:

- Developing the practical education subject in accordance with the Egyptian faculties of education by providing a fifth year for students in which they can be appointed as teachers in governmental schools with a monthly salary rewards and under the supervision of professors of education as well as the expert teachers.

- Attaching an experimental school to the faculty of education to test the modern theories as what happened in 'Al Tabary School' at Ain Shams University.

- Setting up the centers of vocational development as providing teachers who wanted to catch up with the latest Innovations with the training programs.

- Upgrading the academic and educational programs to satisfy the requirements of the work market.

3- There are a lot of steps to be taken before issuing the teachers license:

- Preparing the regulations, ministerial resolutions and regulating bylaws

- Setting a number of the criteria and rules.

- Spreading the culture of vocational accreditation.

- Making the teachers aware of the culture of licensing the teachers' job.

- Preparing school administrations to apply the system of teachers' license.

- It is necessary for the authority which issue licenses to be professionally qualified.

- Issuing a guidebook containing some criteria of the licenses which must be renewed to catch up with the latest the changes. 
- Designing training programs and vocational tests.

- Studying the modern trends in the field of vocational development such as:

1) Focusing on the variable roles of learners.

2) Applying the distance training and virtual one to satisfy the vocational needs of the teachers.

3) Academic accreditation of the programs and the trainers of the vocational development.

4) Considering schools as a unit for the vocational development and the learners' evaluation.

5) Using the new models and developing the teachers vocationally such as teacher-centered model, selfdirected model, leadership model, sequencing steps model and the associative model.

Practical application for issuing licenses for teachers can be done through the following steps:

1-Preparing good infrastructure by building a network between schools, the vocational Academy of teachers and the authority of issuing licenses.

2-Designing a database for all schools and the teachers all over Egypt to specify mechanisms for granting licenses for teachers at work and the new ones.

3-Uploading the models of application forms concerning getting the teachers license explaining the necessary data and the documents to be available for Reading.

4-Empowering the vocational Academy role in providing courses and tests for teachers.

5-Making a partnership between faculties of education, the vocational Academy for teachers and the teachers syndicate to issue licenses for teachers every 5 years depending on the number of courses teachers get in this period.

6-Directing the attention of the principals of the educational process and the principles of the vocational Academy to the importance of the vocational accreditations of teachers to be able to get the job license.

7-Getting a vocational accreditation must be considered a vital condition to work as a teacher. The criteria of accreditation are represented by effective teaching strategies sticking to vocational morals and following the modern teaching methodologies.

8-Putting mechanisms to evaluate the institutions which are concerning issuing licenses and benefitting from feedback to develop their performance.

\section{References}

[1] Filippo, R. F,(2002) Repeating History: Teacher Licensure Testing in Massachusetts, journal of evaluation in education, Vol. 16, Issue 3, p. 211

[2] Beth Hawkins (2016). Minnesota's Board of Teachers Stonewalls Teacher Licensing Changes to the Point of Contemptg July 14 https://www.the 74million.org/article/minnesotasboard-of-teachers-stonewalls-teacher-licensingchanges-to-the-point-of-contempt/

[3] General Teaching Council (2011). Application for qualified teacher status, guidance notes, James Cowana \& Dan Goldhabe (2016). National Board Certification and Teacher Effectiveness: Evidence from Washington State, JOURNAL OF RESEARCH ON EDUCATIONAL EFFECTIVENESS, VOL. 9, NO. 3, 233-258

[4] Motoko Akiba (2013).Teacher Reforms Around the World: Implementations and Outcomes Vol: 19

[5] North Carolina Mentor Program (2010). Beginning teacher guidelines for the 21st century professional public schools of North Carolina, state board of education, department of public instruction, educator recruitment and development division, September.

[6] Sarah Irvine Belson \& Thomas A. Husted (2015). Impact of National Board for the Professional Teaching Standards Certification on Student Achievement, Education Policy Analysis Archives Vol. 23 No. 91, p p. 1-21

[7] Selçuk İlgaz (2019). Pre-Service Social Studies Teachers' Views About Teacher Training (Focus Group Interviews), Journal of Education and Training Studies, Vol. 7, No. 4; April, p p. 204-214

[8] Solvejg Wastvedt (2016). Minnesota teacher licensing system 'broken', Mar 4

[9] Tarman, B., \& Adalar, H. (2016). Comparison of the social studies education teacher training programs of United States and Turkey: Pace and Gazi Unıversity social studies teaching program examples. Abant İzzet Baysal University Journal of Faculty of Education, 16(2), 1603-1630

[10] U.S. DEPARTMENT OF EDUCATION (2018). WWC Intervention Report, National Board for Professional Teaching Standards Certification, 1National Board for Professional Teaching Standards Certification February, p p. 1-44.

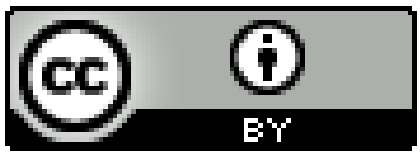

